\title{
A short psychosocial history of British child abuse and protection: case studies in problems of mourning in the public sphere
}

\author{
Andrew Cooper
}

\begin{abstract}
This paper offers a historical and psychosocial account of 'moral panics' about child maltreatment in England over the last four decades, and proposes this perspective as additional to Eileen Munro's more systemic account of the same history. The formal child protection system is theorised in terms of an explicit and a covert dual primary task. The overt task is to actually protect vulnerable children and prevent abuse; the covert task is to protect the remainder of society from exposure to anxiety provoking 'dangerous knowledge' about the prevalence of child maltreatment. Episodes of public and political moral panic occur when the boundaries of containment provided by the official system and its processes are breached, propelling debate and contestation about child maltreatment into the public sphere, where public enquiries and other social mechanisms are called upon to 'settle' the contested issues. Sometimes these social settlements appear to be successful in resolving conflicts about the reality or otherwise of specific forms of abuse; in other cases, especially child deaths, the controversial and anxiety laden-nature of the problem is recurrently projected back into the public domain. The paper suggests that this may be associated with a difficulty about establishing a secure symbolic framework or discourse in society for the emotionally indigestible facts of child torture and murder. In turn this may be associated with problems about the decline of public mourning rituals, and the failure of the public enquiry format to facilitate this. In line with Munro, the paper argues for the importance of a tragic perspective on child maltreatment, to counter idealisations of the capacity of the formal system to protect children.
\end{abstract}

\section{Introduction}

If we step back and try to understand, as a total situation, the phenomenon of child maltreatment and child protection work in England in the $21^{\text {st }}$ century then what do we see? Self-evidently, we are confronted with a cultural and political phenomenon and not just a professional, legal, familial or social scientific one. In this sense child abuse and protection are not unique. Other practices addressed to difficult human predicaments, and which were once largely the preserve of specialised professional, legal and scientific systems, have escaped the boundaries of these same systems and become a focus of intense public, political and cultural debate and anxiety. Autism and its putative link to the MMR vaccine is one instance. Human embryo research and the ethics of human tissue preservation are another. In all such cases where professional and scientific practices are suddenly propelled into the turbulence of the public sphere, the consequences for practitioners, for the ethics of professional conduct, and for research method itself are surely acute and often irreversible. Following a public crisis of these kinds in the domain of practice concerned, things are never the same again. 
Eileen Munro's series of reports (Munro 2010, 2011a, 2011b) into the British child protection system and the reforms she proposed, relied heavily on a systemic analysis of both the problems and solutions. Her arguments are detailed, rigorous, well evidenced and persuasive, and at the time of writing have undoubtedly led to an improved climate for child protection work in Britain. In the context of the historical perspective taken in the present paper, her explanation of the repetitive public crises afflicting the system is interesting:

When society was outraged by the death of Maria Colwell and the series of high profile cases through the 1970s and 1980s, professionals responded by gradually lowering the threshold for intervention to minimise the chances of missing another child in such extreme danger. This necessarily led to more families with low actual levels of abuse being caught up in the net. The cases of Cleveland and Orkney were unsurprising consequences: on these occasions, professionals were criticised for intervening inappropriately and removing large numbers of children from their homes unnecessarily.(Munro, 2010, p. 23)

This is one instance among many she offers of the operation of the law of unintended consequences in systems, and her she deploys it to account for the episodic recurrence of child protection crises in the public sphere.

My own perspective in this paper is different, but not in contradiction with Munro's. Its main themes concern processes, through extended periods of time, of apparent social, professional and intellectual resolution of key conflicts and debates about the nature and existence of some categories of child maltreatment; and processes of irresolution and repetition in relation to some other categories of child abuse. In some instances, the central controversy and the attendant public anxiety and entanglement with this is, as it were, laid to rest. In others it keeps coming back to life. I characterise these processes in terms of a philosophical public dialogue between the specialised professional systems of child protection and the wider public sphere. I then enquire into some explanations for those categories of abuse that refuse to be put to rest, and suggest that these have much to do with issues about the handling of death and mourning in the contemporary public and private spheres. Finally, I offer some thoughts about the connection between these events and the role of myth and myth-making in sustaining our social capacity to process profound existential dilemmas. The paper falls into three main parts that more or less correspond to these themes.

In the few years since the publication of Munro's reports, there has not been a recurrence of the kind of moral panic that attended the deaths of Victoria Climbié or Peter Connelly. Has there been a decisive shift in public and political mood, an acceptance that 'mistakes will sometimes happen' and that as Munro puts it 'prediction and prevention of child maltreatment is necessarily a fallible process' (2011a, p. 96), thus lowering the temperature in the public sphere sufficiently to avoid the need for further eruptions of public anxiety - moral panics as they are often labelled? 
Despite the parallels with episodes of public turbulence and scrutiny of specialised professional practices in other domains, I believe that this wider cultural history of English child maltreatment and protection and its consequences for everyday practice is distinctive and probably unique. I want to suggest that child protection controversies constitute a 'limit case' of the processes I have alluded to above and that careful analysis of the complex dynamics involved may yield findings of much wider social significance.

\section{The two tasks}

What is a system of child protection for? What is a system for the protection of any group of vulnerable people for? I want to propose that it has at least two primary tasks, but that the tension between these can be a source of acute difficulties, and that in the English child protection system this tension lies at the heart of a real crisis. The crisis takes the form of a paradox or contradiction, in fact a number of paradoxes. On many indices, including international comparisons, the system does quite well at protecting children from extreme and life threatening abuse and violence. Research by Colin Pritchard and Richard Williams (2010) suggests that child abuse related deaths in the UK have been declining steadily for the last 30 years, and at a significantly higher rate of decline than all causes of child death. But the experience of those working in the system is different - from the perspective of front line workers, and their managers it is teetering on the brink of collapse, hanging on by its fingernails. And this experience has been getting steadily worse. Why is this?

In the week when the 'Baby P' crisis was at its height in 2010, I wrote an article in a national newspaper and found myself engaged in a number of media appearances as a result. The most intelligent conversation I felt I had all week was with a London cab driver as I was on my way to a radio interview. I was apprehensive about his reaction when I told him what I was about to do - London cabbies not being especially well known for their liberal views. But he said, 'I can't read about that case in the papers - it's too distressing...I couldn't do that job, I wouldn't be able to sleep at night'. He laughed a little nervously and looked at me in the mirror, and said 'I suppose I wouldn't have been a very good social worker'. But he had his finger on something important - one thing social workers and others in the child protection system do at a societal level is help people sleep at night; not because we are defending the realm against communists, terrorists or insurgents, but because we are protecting people from the emotional impact of knowing about the torture and murder of babies that may be happening just down the street from where each of us lives.

Thus my hypothesis is that the covert or unconscious primary task of the child protection system is to manage, on behalf of the rest of adult society, our deep ambivalence about children, about parenting, and about the propensity in all of us to feel like doing violence towards our own children; in other words 
the ubiquity of hatred within the ordinary, everyday job of parenting. This is a largely unacknowledged reality in our society, and a difficult one to 'evidence' Here I offer just one or two morsels starting with a few lines from the novelist Rachel Cusk's (2002) uncomfortably honest book about her experience of motherhood:

Looking after children is a low status occupation. It is isolating, frequently boring, relentlessly demanding and exhausting. It erodes your self esteem and your membership of the adult world. The more it is separated from the rest of life, the harder it gets...As a mother you learn what it is to be both martyr and devil. In motherhood I have experienced myself as both more virtuous and more terrible, and more implicated too in the world's virtue and terror, than I would from the anonymity of childlessness have thought possible.

(Cusk R., 2002: 7-8)

However, for a significant proportion of the population official or media recognition of child maltreatment will not be functioning as a vehicle to assuage conscious or unconscious anxieties or fears (It's OK, the real abusers are over there and being dealt with by those social workers), but as a representation of real experiences of abuse, known to them, but not disclosed or investigated, and hence beneath the surface of public awareness. How come?

Child maltreatment remains a major public-health and social-welfare problem in high-income countries. Every year, about $4-16 \%$ of children are physically abused and one in ten is neglected or psychologically abused. During childhood, between $5 \%$ and $10 \%$ of girls and up to $5 \%$ of boys are exposed to penetrative sexual abuse, and up to three times this number are exposed to any type of sexual abuse. However, official rates for substantiated child maltreatment indicate less than a tenth of this burden.

(Gilbert et al. 2008, p. 1)

So, up to ten times the amount of child abuse ever reported or investigated in Britain is lurking somewhere just beneath public, judicial, community, or professional awareness. What might be the contribution of the population of abusing adults, and young people, as well as unidentified victims of abuse to eruptions of public outrage and anxiety when a child abuse case hits the headlines? In her psychoanalytic study of the Paulsgrove Estate antipaedophile vigilante movement, Jessica Evans (2003) reveals that a high proportion of the women who whipped up the campaign against a fantasised 'list' of locally resident paedophiles were themselves well known to children's services because of child care concerns.

The women made definite secondary gains from putting themselves in the position of the persecuted, once they had projected all the destructiveness onto the paedophile other. Strengthened by the group, 
individuals achieved a position of moral rectitude that left them feeling omnipotent, and in control.

(Evans, 2003: 177)

If we extend the principles of this analysis, then a second unacknowledged primary task of the child protection system is not just to be a container for universal anxieties and ambivalence of the kind that Rachel Cusk gives voice to, but as a site for the collective projection of denial about actual abuse that goes unreported or un-investigated.

\section{Truth, knowledge and fantasy: a social dialogue (a) The Cleveland Crisis}

I suggest that each time society is confronted anew with awareness of something like the actual prevalence of abuse in its midst, the impact of this new knowledge is traumatic in some meaningful sense of that rather abused word. Of course the truly traumatic events - such as the widespread intrafamilial sexual abuse of children - have already occurred; but our collective capacity to tolerate knowing about this may not be securely established; so much so that there may not even be a language, an available conceptual apparatus or discourse with which individuals or society can think about such matters. A kind of social repression barrier is operating.

I suggested earlier that the consequences of repeated explosions of public and political concern about single cases of child abuse or death have been negative for the capacity of the professional system to function. But there is another side to the story. In diagram 1 , I represent what I see as certain very turbulent, but positive processes in which the specialised system of child protection was pressed into a complex philosophical dialogue with the remainder of society. The Cleveland crisis of 1987 is the first example. With Cleveland there really was a world before and a world after. In the course of a few turbulent months as the extraordinary events in Cleveland unfolded, our world changed, and changed I believe decisively for the better. The fact of widespread intra-familial sexual abuse in our society became established, accepted. But not without a tremendous struggle; I think it is easy to forget how ill equipped we were in 1987 as a society and as individuals to cope with the emergence into social awareness of this most disturbing of social facts. In retrospect it can seem as though a capacity to tolerate painful and unwelcome truths won out in a contest with the impulse to deny them, and to label the truth seekers mad. While this is accurate, and that this was a crisis in which an opportunity for civilised progress was seized, I also believe we forget that at the time most of us were truly uncertain about the status of the disclosures and revelations which were emerging. Sexual abuse as a widespread social reality was breaking through a social repression barrier.

\section{Diagram 1}




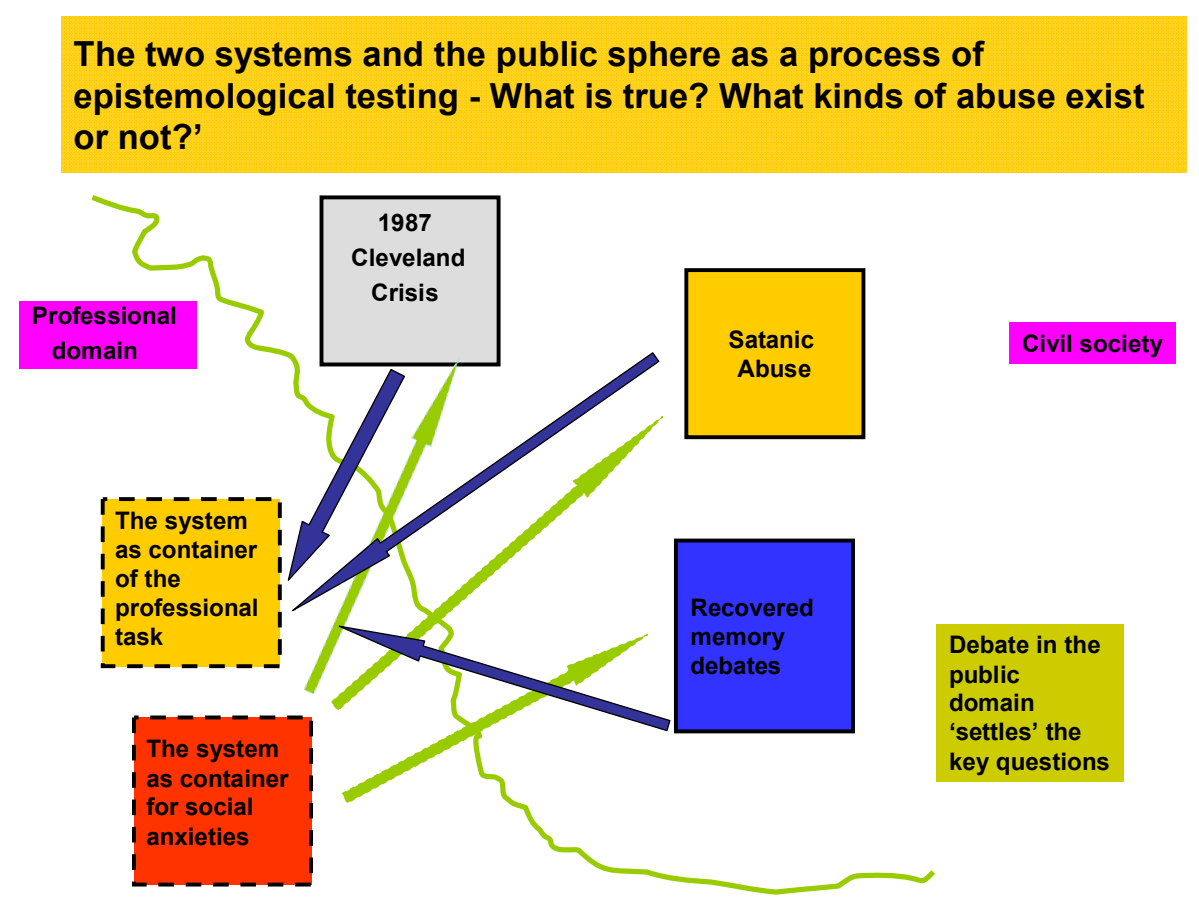

However, I believe that Cleveland became a social 'crisis' not just because new and disturbing facts were emerging into the daylight, but also because these 'facts' sometimes transpire to be inherently uncertain in their nature, independently of any social, political, ideological or organisational pressure brought to bear by interested parties in the context of their emergence. In certain circumstances in sexual abuse, no-one, not even the victim, may be sure 'what happened'. This fact - the fact of inherent possible indeterminacy or undecidability with respect to historical truths about abuse seems to me to be an important but under-recognised component in the construction of the crisis. We like to, or even need, to have a sense of certainty about such profound matters. True, false, it happened, it didn't happen. It may be true, as Freud claimed, that the incest taboo is the foundation stone of civilisation, securing the boundary between reality based and fantasy based social and psychological functioning, but it then follows that where this boundary has been violated, something fundamental about our grip on the epistemological foundations of civilisation will be compromised. This is a pretty frightening discovery. The predicament is alluded to in the report of the public inquiry into the Cleveland affair:

The concept of helping the child to tell (of sexual abuse) is recognised to have its uses in certain circumstances. When embarking on it for diagnostic purposes, it is important to remember at least three possible situations:

1. The abuse has occurred and the child is speaking of it.

2. The abuse has occurred and the child is unable to speak of it or is denying it. 
3. The abuse has not occurred, and the child cannot speak of it.

It is clearly a difficult matter of judgement to know whether the child is not telling because of some sort of pressure, such as fear of the consequences, or because there is nothing to tell. At the end of a session, the professionals may not know which of those two situations is the true position.

(HMSO, 1988, pp 206-207)

However, after a period of testing in the public domain, in the courts and the inquiry process itself, something like a 'true' overall position was settled upon. A large majority of cases of suspected sexual abuse were deemed to have been based in some reality. The Butler Sloss enquiry effectively 'settled' the contest about whether intra-familial sexual abuse was a 'fantasy' or a 'reality' and there has been no subsequent publicly endorsed effort to overturn this 'settlement'.

\section{(b) Satanic Abuse}

The second episode concerns what became known as 'Satanic abuse'. This, as some may recall was one dimension of the Orkneys crisis, but there were other sites of alleged exposure of Satanic abuse - especially in Rochdale and Nottingham. If the fact, the existence or otherwise, of child sexual abuse was temporarily and fiercely contested during the Cleveland affair, then the Satanic abuse disclosures led to even more controversial contestations. Broadly, and I suspect correctly, the weight of official evidence and opinion eventually settled on a judgement that the most extreme features of allegations of Satanic abuse were a kind of hysteria or group fantasy; but along the way, some careful distinctions were established - the evidence for ritual abuse, and systems of organised child abuse became better accepted and understood, but the more lurid allegations associated with Satanic abuse - sacrificial baby murder, cannibalism, drinking the blood of murdered children - were rejected. In thorough international studies not a single shred of forensic evidence was discovered to support these claims. There are some pretty respectable child mental health professionals who would dispute this outcome even today. Who is actually right, if there is an absolute right and wrong in this very murky area, is a matter of great importance. But in this paper I am more interested in describing the rather unusual processes via which the questions involved are 'tested'.

To give us a flavour of where the controversy came to rest here is one of the conclusions of Jean La Fontaine's research study, commissioned by government to try to investigate the allegations and settle the debate:

3. Rites that allegedly include the torture and sexual abuse of children and adults, forced abortion and human sacrifice, cannibalism and bestiality may be labelled satanic or Satanist. Their defining characteristic is that the sexual and physical abuse of children is part of rites directed to a magical or religious objective. There is 


\section{no evidence that these have taken place in any of the 84 cases studied. (original emphasis)}

(La Fontaine 1994, p. 30)

So, we are in familiar territory in many respects - truth, denial, or undecidability - issues which child protection workers and the courts struggle with every day But in the period under discussion, the emergent claims in relation to both child sexual abuse and Satanic abuse were projected across the boundary of the professional practice system, beyond the remit of local judicial procedure or media debate, and were then subject to processes of very public national media, legal and research scrutiny. The Cleveland Inquiry itself, chaired by Justice Butler-Sloss, was obliged to engage at points with the deep philosophical issues to which I have alluded - what kind of thing actually exists in this area and how secure are our knowledge claims in relation to these phenomena - questions that philosophers would call 'ontological' and 'epistemological' respectively. Satanic abuse was the subject of a commissioned and careful research study by, interestingly, a distinguished social anthropologist, Jean la Fontaine, who was in effect asked to settle similar questions - does this alleged phenomena exist and what evidence supports the conclusions reached.

To establish and create social acceptance of new and disturbing social facts of this kind, and to arbitrate conclusively on the status of some closely related social fantasies, are considerable social achievements - assuming the correct judgements were reached. The next phase of public engagement with these issues was perhaps more concerned with meaning and its relationship to historical truth and/or fantasy.

\section{(c) Recovered memory}

Debate about 'recovered memories' of abuse surfaced in association with the events just recounted, as a kind of third phase of social engagement with the whole terrain. Historical details differ in different countries and the North American narrative varies from Britain, but in the latter the trajectory is roughly: Cleveland 1987-88, Satanic abuse (in Britain) 1990-1991, recovered memory 1992-5 with a significant conference on the subject organised by the Psychoanalysis Unit at University College London in 1994. The conceptual complexity of the recovered memory terrain is quite well summarised in the following diagram, taken from a chapter of the book reporting the proceedings of that conference: 
Diagram 2 The relationship between true/false memories and 'actual abuse

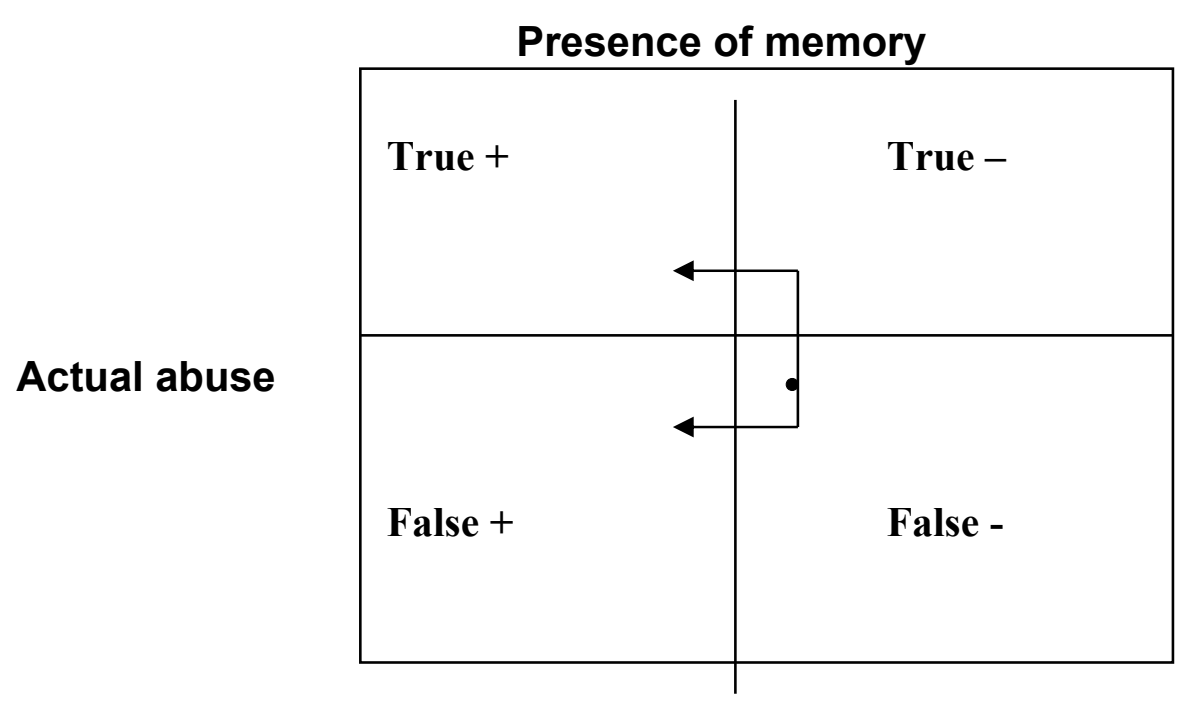

Before the recovery (of memory) we do not know whether there was or was not genuine abuse historically, so the supposedly unrecovered information is placed in a neutral position between a false negative and a true negative. The decision is what status to assign to it when it becomes described by the accuser as a genuine memory: is it a truepositive memory or a false-positive memory? The crux of the argument is that the accusers and their therapists are claiming that a false negative becomes a true positive, whereas the False Memory Society parents - who insist on their innocence - are claiming that a true negative becomes a false positive. Both parties can be, and we must assume usually are, absolutely sincere. We cannot settle the matter by a show of hands, or even by a lie detector.

(Weiskrantz, 1997, p.7)

Drawing on psychological research into memory and memory recall, the same author concluded that 'retrospective analysis of memory in relation to historical events without external corroboration is forever doomed to an uncertain conclusion' (1994: 21) and a psychoanalyst commenting on this paper remarked that 'Perhaps this is one of the hardest things for us - dealing with uncertainty, with having to tolerate not knowing, and not being able to clarify.' (Trowell, 1997: 25)

But the personal stakes are high, and people pursued certainty in many individual cases through the courts. In her book Hystories: Hysterical epidemics and modern culture, Elaine Showalter tells us that: 
By 1994 over three hundred cases involving repressed memory had been filed in the American courts. George Franklin was convicted of murder in 1990 and sentenced to life imprisonment when his daughter Eileen "remembered" seeing him kill a child in 1969 - a conviction overturned five years later when (the Judge) cited improprieties in the trial and the scientific problems of recovered memory evidence.

(Showalter 1997:146)

Once again, we are in territory broadly defined by the parameters of truth, denial, absolute or partial undecidability, and the tolerance or intolerance of uncertainty. Given this, it is something of a paradox in my account that all of the specific categories of controversy I have so far cited - child sexual abuse, Satanic ritual abuse, and the so-called memory wars that began with recovered memories of abuse, have largely subsided as a focus of public or indeed significant professional preoccupation. We accept the reality of, and continue the journey of individual and collective disclosure with respect to child sexual abuse; I am unaware of Satanic abuse as an element in any case coming to professional attention for many years; and the problem of memory and its relation to historical 'truth' has receded into the sequestered space of the consulting room where possibly we are all a little wiser for the intense contestation that occurred. On the other hand, intermittent public turmoil persists concerning those child abuse cases in which there is little or no ambiguity involved, because the child is dead, murdered, often following terrible torture.

Put like this, it does not seem surprising that child abuse and protection become a focus of public concern from time to time. But it is the 'time to time' aspect of it that is in part perplexing. The most obvious, and widely accepted explanation for oscillation between public and media indifference and intense but short lived concern, is what could be termed the 'failure' hypothesis. Eruptions of public and media concern occur because, and only because, evidence of professional failures to prevent the preventable in these cases come to light. This is complicated territory - we know that in Britain about 50 children a year die at the hands of their parents or immediate carers, and that many of these cases involve what could readily be (re)constructed as 'professional failures', the now familiar recounting of 'missed opportunities' to intervene. But year on year, these cases, let alone the many more where children are severely injured, attract little or no pubic or national media attention. No 'crisis' ensues. Equally, other public services make mistakes that result in avoidable death - they even seek out and kill innocent people - but entire professions are not vilified in the public mind as a result. Who has heard of police officers or doctors (completely un-associated with the events in question) being spat at in the street, or where they are associated named and shamed on the front pages of national newspapers?

So, it is tempting to think that the repetitious character of child death crises in Britain is mostly explained by a toxic blend of an intrusive and scandal hungry media, a weak social work profession, and occasional instances of egregious and repeated failures to protect vulnerable children. What receives less 
attention is the idea that these crises are more directly associated with our response to children themselves, and the deaths of particular children, and their terrible suffering at the hands of adults of which we learn.

\section{(d) Child deaths}

There are different points at which this familiar narrative could be said to begin. I take the series of child deaths in the 1980s that became the subject of high profile public inquiries as a point of departure. Jasmine Beckford, Kimberley Carlisle, Tyra Henry. Everywhere, in the wake of each of these inquiries, procedures were tightening, volumes of new guidance and procedure being written, risk assessment protocols drafted. Such was the dominant policy response, one with which we are now so familiar that it is hard to imagine it could be different. The story continues through the 1990s and into our own decade; periods of relative calm and re-grouping when the work of child safeguarding professionals is mostly beneath the social radar, punctuated by dramatic explosions. Each time one of these eruptions occurs, government reacts to public outrage and panic by constructing a further set of rigid procedural or quasi-judicial defences, and projecting them back into the professional system, where they are at best ambivalently received, but never openly challenged. To a psychotherapist, they appear to be obsessional defences - a lot of ritual checking and re-checking, with an increasing uncertainty about what we are checking for (Cooper and Lees, 2014, forthcoming).

The obsessional quality of the procedural solutions each inquiry mandates are a reaction characterised I suggest by a kind of excess rationality, a blind faith in the power of rules to manage and contain the social panic that exposure to the excessively painful and disturbing details of a child murder, and the proximity of someone who might have prevented it but did not, provokes in all of us. Would we have done better, or differently? The thought that we might not have done better is unbearable; the false conviction that we certainly would have done better, evokes triumph and rage. The result, the now familiar pronouncement that government will put in place measures to ensure that a dreadful tragedy like this 'never happens again'.

But it does keep happening - children continue to be murdered and from time to time news of one of these murders escapes the local professional domain where they are, as it were, routinely if very painfully assimilated, and a further public crisis ensues.

Thus, Diagram 3 aims to show how recurrently, when controversy and anxiety associated with particular child deaths is propelled out of the realm of the formal child protection system, into the public domain (the jagged grey line represents the boundary), the findings and recommendations of enquiry processes are then propelled back into the official system. The overt task of the system is rendered more difficult, as a result of the 'failure' of the 'covert' task to protect the wider public from awareness and knowledge.

\section{Diagram 3}




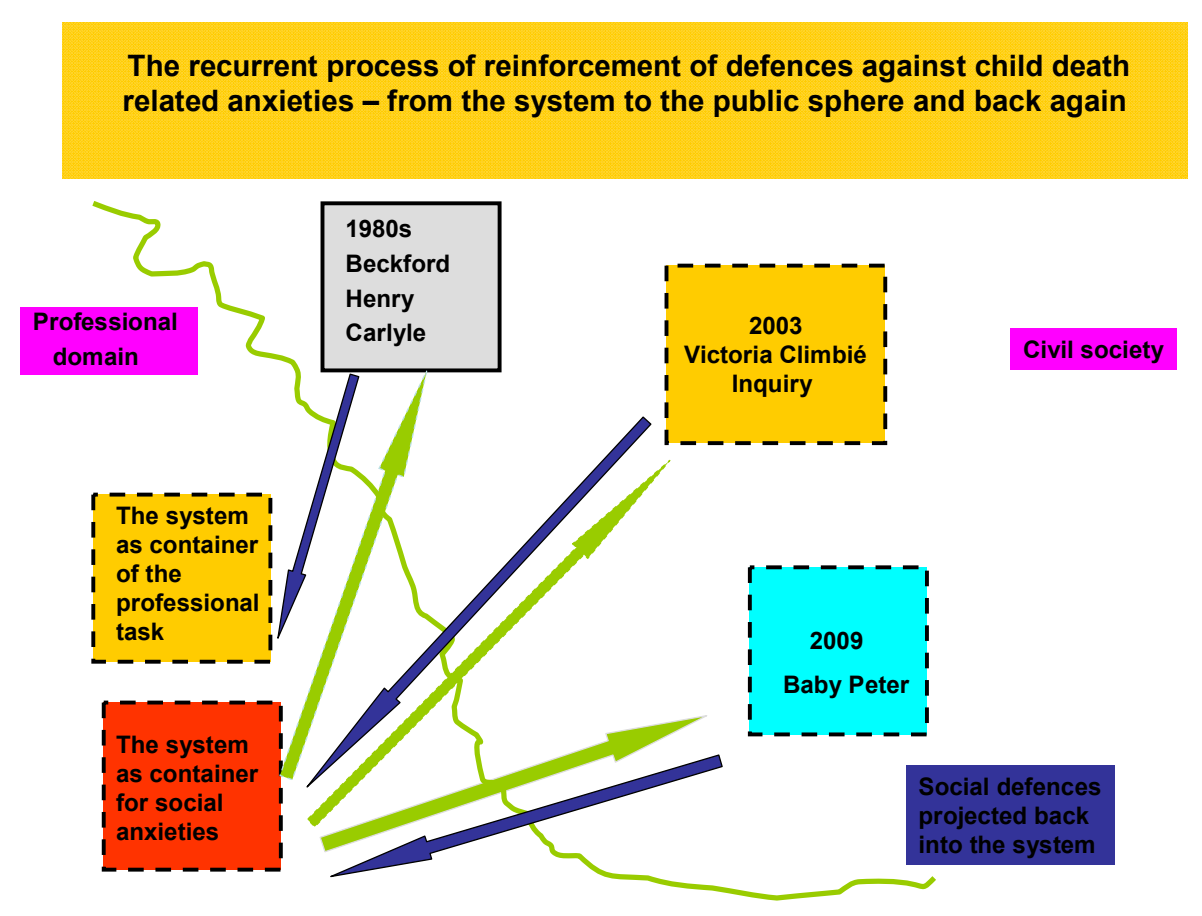

\section{Mourning and its relationship to child death}

It was during the Victoria Climbié inquiry that it first occurred to me that the inquiry itself, culminating in the publication of the report, might constitute an unrecognised process of public mourning. To me it is striking how in every public inquiry process and accompanying media storm, the ordinary emotional registration of the death of the child is lost, or obscured behind the intense preoccupation with questions of blame, accountability, retribution, reconstruction of missed opportunities and so on. And yet, over the last three decades, the names of perhaps half a dozen of these same children have become inscribed in public memory and discourse, and the (to coin a phrase) often monumentally long and weighty reports of the inquiry into their deaths sit in every academic and many public libraries. Beyond, somewhere out of public reach are the memories of all the others who died similar deaths, but attained no such collective recognition. Like the tomb of the unknown soldier, does each of these inquiries and reports become the one that stands for the many?

In his book The New Black: Mourning, Melancholia and Depression Darian Leader devotes much interesting space to the relationship between public and private mourning. I take this quote as just one of many possible useful points of departure:

Most Western human beings in fact watch images of death every night in the TV shows about crime scene investigation and murder that fill up the evening programme schedule. It is amazing to realize that this is what most people do after work: 
they watch programmes in which someone dies and whose death is subsequently explained and made sense of. The fact that this is reiterated endlessly suggests that death is ultimately not something that can be made sense of. And that the increasingly violent images multiply in the absence of a symbolic framework that might mediate them.

(Leader, 2008:74)

Do we possess a public symbolic framework to make sense of, mediate, child murder and torture in our society? I suspect not. The first part of this paper suggested that each eruption of new awareness in relation to child abuse Cleveland, Satanic abuse, recovered memories - was succeeded by a process via which pubic institutions were engaged in an effort at some sort of 'sense making', and that the evidence is these may have been broadly successful. The wearisome and professionally damaging repetition of eruptions over several decades with respect to child deaths suggests something else, but what? Darian Leader takes an observation of Melanie Klein's about internal processes of mourning as the departure point for his discussion of the private-public relationship that he calls 'a dialogue of mournings':

In the mourner's state of mind, the feelings of his internal objects are also sorrowful. In his mind they share his grief in the same way as actual kind parents would. The poet tells us that "Nature mourns with the mourner"'

(Klein, 1940, p. 359)

Contemporary controversies over the phenomenon of public mourning are telling here, says Leader. Critics of, say, the outbreak of public mourning at the death of Diana Princess of Wales, who characterised the public demonstrations of grief as cynical or inauthentic are missing the point. No-one really could seriously argue that these tears are (only) for the dead figure themselves. Rather, he says, 'it is the public framework that allows people to articulate their own grief for other, unrelated losses... This is a basic function of public mourning rituals. The public facilitates the private'. (2008, p. 77 ) On this argument we could recognise the now widespread public practice of establishing temporary shrines at the site of a death or loss - road accidents for example - usually in the form of collections of flowers, as an effort to establish or re-establish a wider public symbolic framework for mourning than private burial rites allow.

Darian Leader explores the many vicissitudes of the mourning process both intra-psychically, and socially, via the anthropology of mourning rituals in various societies. In some societies these rites entail a concrete re-ordering of social relationships in the community 'After mourning and burial rites, social structures change, and formal rules govern the new set of ancestors to their descendants. The key is that the dead are installed in the ancestral line.' To 
achieve this, he argues that the dead must be killed a second time. '(F)or the living to feel safe and secure, the dead have to die twice. Real biological death is thus different from proper symbolic death.' (2009, p. 116) We might think here both of the impulsive and reactive re-ordering of professional systems that usually follows inquiries, and of the inevitability, as we put it, that 'heads will roll' somewhere in those same systems. Only then, at a public level, can the symbolic death be secured.

The core thesis I have been outlining in this paper is that the social history of child abuse in Britain is about a gradual and episodic struggle to accommodate new and disturbing knowledge of ourselves, and along the way to better delineate reason from unreason. It involves a rather Hegelian idea of social science as the unfolding of society's consciouness of itself. But if, as Leader suggests, we cannot ultimately make sense of actual death, are we condemned forever to repeat the history of our knowledge of child torture and death in the manner of Jasmine Beckford, Victoria Climbié and Peter Connelly? The view I am tentatively proposing suggests that our monuments to these children are in some respects a symbol of progress - it has taken repeated single cases to achieve it, but on this view no-one can any longer doubt it: child murder keeps happening; but the violent, unpredictable, primitive social processes that attend their installation suggests otherwise: child murder keeps happening but only because incompetent professionals take their eye off the ball.

In the closing part of this section of the paper I propose that the notion of tragedy is the lost idea that might guide us towards the development of 'a symbolic framework that mediates' these eruptions.

\section{Tragedy - the unacceptable face of modernity}

Tragedy is an unfashionable idea, perhaps too associated with an attitude of complacency, of passivity in the face of 'fate'. It has resonances of an old world, an old social and moral order, from a time before the optimism of reason declared that 'there are no accidents', we can subdue our monsters for ever, ensure it never happens again; and in which, as the sociologist Zygmunt Bauman put it, 'contingency, accident and fate are deeply resented'.

And there are more than enough reasons for the consciousness of mortality to be traumatic. First and foremost, thinking about death defies thought itself... reason's power is to be a guide to good choice, but death is not a matter of choice. Death is a scandal, the ultimate humiliation of reason.

(Bauman, 1992, 14-15)

Tragic drama has been a key symbolic framework for mediating this fact. But the problem afflicting the great figures of tragic drama is not that their characters are 'flawed', but that they do not know themselves to be flawed Lady Macbeth's overweening ambition, Macbeth's propensity to be bullied by her. If redemption arrives, it is in the form of self-knowledge, not the attainment of perfection: 'I am a very foolish, fond old man', says Lear 'and to 
deal plainly I fear I am not in my perfect mind,' (Shakespeare, 1963, p. 161). 'Nobody dast blame this man. A salesman is got to dream, boy. It comes with the territory', says one character at the graveside of Willy Loman in Arthur Miller's Death of a Salesman (Miller, 1958, p.222). Of course, these reflections bring me to the troubling intersection between an account that seeks to look beyond the surface public discourses and practices that attend such grave matters as the murder of a child, and our social and professional need for those same discourses and practices. We may draw the line at murdering social workers, police officers or chief executives who are deemed to have failed in the course of their public duty - though an alarming proportion of the population seem inclined not to draw this line - but retrospectively based criticism or critical interrogation of their practices is the norm.

But if nothing resembling the notion of 'tragedy' is available to mediate this pressure, the imperative towards production of a retrospective explanatory account that says 'Events could or would have been otherwise if $\mathrm{x}$ had done $y$ ', and therefore ' $x$ should have done $y$ ' and so 'The world should be otherwise than it is' is irresistible. There is much more to say about this particular, and inadequate, line of epistemological reasoning. For example it seems to me to substitute a model of social reality as a closed and linear system, for one that is open and non-linear and in better accord with lived experience as an unfolding set of possibilities and choices. So here, we find ourselves in close agreement with Eileen Munro's own analysis of the situation:

The big problem for society (and consequently for professionals) is establishing a realistic expectation of professionals' ability to predict the future and manage risk of harm to children and young people. Even when it is ascertained that abuse or neglect has occurred, there are difficult decisions to make about whether the parents can be helped to keep children safe from harm or whether the child needs to be removed. Such decisions involve making predictions about likely future harm and so are fallible. It may be judged highly unlikely that the child will be re-abused but low probability events happen.

It is important to be aware how much hindsight distorts our judgment about the predictability of an adverse outcome. Once we know that the outcome was tragic, we look backwards from it and it seems clear which assessments or actions were critical in leading to that outcome. It is then easy to say in amazement 'how could they not have seen $x$ ?' or 'how could they not have realised that $x$ would lead to $y$ ?' Even when we know the evidence on the hindsight bias, it is difficult to shift it; we still look back and over-estimate how visible the signs of danger were. The hindsight bias:

'oversimplifies or trivialises the situation confronting the practitioners and masks the processes affecting practitioner behaviour before-the- 
fact. Hindsight bias blocks our ability to see the deeper story of systematic factors that predictably shape human performance' (Woods, D. et al. (2010), Behind Human Error, 2nd Edition, pp15, Farnham, Ashgate.)

(Munro, 2011b, p.18, original emphasis)

Here I want principally to note that these frameworks of analysis also serve to eradicate the space of loss and mourning, a confrontation with the fact that one kind of event is absolutely outside our control - the certainty of death.

\section{Conclusion}

Eileen Munro's series of reports into child protection work in Britain are almost revolutionary, breaking a decades long mould of bureaucratic, conceptually linear and essentially positivist public policy interventions. Her aims went far beyond simply patching up the damaged state of the system and the social work profession following the Peter Connelly crisis, to embrace a fundamental change in cultural and political sensibilities. How successful she will prove to have been in these ambitious aims, it is still too early to adjudicate. The present paper does not set out to suggest that her analyses are in any way mistaken or misplaced, but it does propose that there are deeper, wider and more intangible forces at work in our society driving what has seemed like a 'repetition compulsion' with respect to chid maltreatment scandal-making, and that we should be prepared for the fact that in British child protection work history keeps repeating itself, always as tragedy, never as farce.

\section{References}

Bauman Z. (1992) Mortality, immortality and other life strategies, Cambridge. Policy Press

Cooper A. \& Lees A. (2014, forthcoming), 'Spotlit: Defences against anxiety in contemporary human service organisations', in Rustin M. and Armstrong D. (eds) London, Karnac Books

Cusk R. (2002) A Life's Work: On becoming a mother, London. Fourth Estate

Evans J. (2003) 'Vigilance and Vigilantes: Thinking psychoanalytically about anti-paedophile action ', Theoretical Criminology (7.2), pp. 163-89

Gilbert R., Spatz Widom C., Browne K., Fergusson D., Webb E., Janson S., (2008) 'Burden and consequences of child maltreatment in high-income 
countries' The Lancet, published on line at www.thelancet.com 03.12.08 DOI:10.1016/S0140-6736(08)61706-7

HMSO (1988), Report of the Inquiry into Child Abuse in Cleveland 1987, London: Her Majesty's Stationery Office.

Klein M. (1940) 'Mourning and its Relation to Manic-Depressive States', in Klein M. (1975) Love, Guilt and Reparation, London. Hogarth

La Fontaine J. (1994) The Extent and Nature of Organised and Ritual Abuse: research findings, London. HMSO

Leader D. (2009) The New Black: Mourning, Melancholia and Depression, London. Penguin

Miller A. (1958) Death of a Salesman, in Collected Plays: Arthur Miller, London. Cresset Press

Munro, E. (2010), The Munro Review of Child Protection - Part One: A Systems Analysis, London: Department for Education.

Munro, E. (2011a), The Munro Review of Child Protection: Interim Report, London: Department for Education.

Munro, E. (2011b), The Munro Review of Child Protection : Final Report, London: Department for Education.

Pritchard C. \& Williams R., 'Comparing Possible "Child-Abuse-RelatedDeaths" in England and Wales with the Major Developed Countries in 19742006: Signs of Progress? British Journal of Social Work, 40 (6), pp.1710-18

Shakespeare W. (1963) King Lear, London. The New English Library Limited

Showalter, E. (1997), Hystories: Hysterical epidemics and modern culture. London: Picador. 
Trowell J. (1997), 'Discussion', in SandlerJ. \& Fonagy P. (eds) Recovered Memories of Abuse: True or False?, London. Karnac. Pp. 22-5

Weiskrantz L. (1997) 'Memories of abuse or abuse of memories?' in SandlerJ \& Fonagy P. (eds) Recovered Memories of Abuse: True or False?, London. Karnac. Pp. 3-21 